\section{La comunicación}

\section{desde los enfoques latinoamericanos}

\section{Communication from the Latin American approaches}

DOI: http://dx.doi.org/10.18566/comunica.n41.a02 Fecha de recepción: 15 de septiembre de 2019

Fecha de aceptación: 30 de octubre de 2019

\section{Resumen}

A diferencia de lo que sucede con las teorías comunicacionales euroestadounidenses, las desarrolladas por autores de América Latina (expresadas en este artículo en los enfoques teóricos) se inscriben de forma manifiesta en los problemas y desafíos de la región. Ello hace que se caractericen por una concepción crítica y se orienten por diseños de futuro que anticipan una sociedad democrática con derechos.

Esa visión es presentada aquí como producto del análisis de un conjunto de propuestas de conceptualización de la comunicación hechas por pensadores de Argentina, Bolivia, Brasil, Colombia, Chile, México, Paraguay, Perú, Uruguay y Venezuela durante las décadas de 1960 a 2000. Esta teorización situada, que define una comunicación asentada en el diálogo, con participación y en condiciones de igualdad, es la base de lo que acá se considera la episteme comunicacional latinoamericana.

\section{Abstract}

Unlike what happens with Euro-American communication theories, those developed by Latin American authors (expressed in this article in theoretical approaches) are manifestly inscribed in the problems and challenges of the region. This means that they are characterized by a critical conception and are guided by future designs that anticipate a democratic society with rights. This vision is presented here as a product of the analysis of a set of conceptualization proposals of communication made by thinkers from Argentina, Bolivia, Brazil, Colombia, Chile, Mexico, Paraguay, Peru, Uruguay and Venezuela during the decades from 1960 to 2000. This situated comunicación

número 41

Julio - diciembre

2019 | pp. 11-21

\section{Erick R. Torrico Villanueva}

Doctor en Comunicación por la Universidad Rey Juan Carlos de Madrid. Director académico de la maestría en Comunicación Estratégica de la Universidad Andina Simón Bolívar, La Paz (Bolivia). Expresidente de la Asociación Latinoamericana de Investigadores de la Comunicación. Autor de varios libros sobre periodismo, comunicación y democracia, teorías e investigación comunicacionales. ORCID: https: / / orcid. org/0000-0003-1237-9241 etorrico@uasb.edu.bo

Palabras clave Comunicación, América Latina, Enfoques teóricos, Crítica utópica, Episteme.

\section{Key words}

Communication, Latin America, Theoretical approaches, Utopian criticism, Episteme. 
theorization, which defines a communication based on dialogue, with participation and on conditions of equality, is the basis of what is here considered the Latin American communication episteme.

\section{Introducción}

El hecho comunicacional y su conceptualización adquieren en América Latina ${ }^{1}$ una connotación de subversión y utopía que no es hallable en otros contextos.

Así, las teorías prevalecientes internacionalmente en la materia, que dan cuenta abstracta de las prácticas predominantes a la vez que las ordenan en su realización cotidiana, no suelen explicitar sus orígenes ni intereses y son, por lo general, presentadas como la única posibilidad comprensiva válida e, incluso, neutra.

Frente a ese pretendido universalismo, el pensamiento teórico crítico desarrollado al respecto en el caso latinoamericano no solo se muestra como una visión comprehensiva alternativa, sino que, además, deja al descubierto su inserción en la problemática histórica de la región.

Fue con ese carácter que hace más de medio siglo pensadores, de y en Latinoamérica, comenzaron el cuestionamiento de las ideas establecidas por autores estadounidenses y europeos en relación con el hecho comunicacional (Atwood \& McAnany, 1986; Fuentes, 1991; Beltrán, 2000 y 2007; Marques de Melo, 2007; Gobbi, 2008; o Torrico, 2016a), y propusieron otros puntos de mira que, en parte, se traducen en lo que acá se presenta como los "enfoques latinoamericanos". Estos consisten en un conjunto de aproximaciones conceptuales que surgen tanto de la realidad concreta vivida en el área como de proyectos de autonomía, identidad y humanización.

Un examen de la producción intelectual de 41 autores de 10 países de la región y de dos latinoamericanistas (uno europeo y otro estadounidense) permitió identificar los enfoques propios, expuestos más adelante, y posibilitó su respectiva caracterización. Para el efecto, se utilizó el análisis crítico del pensamiento teórico, técnica dirigida a establecer la filiación epistemológico-teórica y sociopolítica de las conceptualizaciones generadas por los comunicólogos que fueron objeto de observación y cuya labor se desplegó entre las décadas de 1960 y 2000.²

La contribución teórica latinoamericana a la comunicación se asienta en una comprensión comprometida de las particularidades y desafíos de la circunstancia regional, pero también, por supuesto, en la búsqueda de la
1 Esta denominación, que refiere al conjunto de pueblos asentados en el territorio que cubre desde la Patagonia argentino-chilena hasta la frontera mexicanoestadounidense, es asumida aquí como descriptiva de la identidad regional. Sin embargo, este nombre está hoy sujeto a discusión. Una propuesta de cambio interesante es la de Abya Yala/ Afro/Latino-América (Escobar, 2018), que resulta más integral y expresiva de la diversidad histórica y étnico-cultural propia del área.

2 Sobre la nómina completa de las autoras y los autores estudiados, los detalles de la técnica investigativa aplicada y los correspondientes aspectos contextuales, consúltese Torrico (2016a). 
autoafirmación frente a las influencias foráneas (por ejemplo, Beltrán, 2000, pp. 87-122).

\section{América Latina como lugar epistemológico}

Como afirmaba René Zavaleta (1988, p. 148), “Uno conoce, naturalmente, desde lo que es", y ser implica estar; por tanto, el conocimiento es siempre situado, lo que, a su vez, en el análisis social (y, por tanto, en el comunicacional), remite a la historicidad.

Leopoldo Zea (2006, p. 12) sostiene que la historia de las ideas de Latinoamérica es "la historia de un irse apartando paulatinamente de los modelos importados" y de la paulatina formación de una suerte de conciencia nacional regional que "se traduce en una búsqueda afanosa de identidad" (Zea, 2006, p. 12).

Desde este punto de vista, América Latina se constituye en un "lugar epistemológico", razón por la cual el conocimiento posible hecho desde la región tiene la impronta de una inserción social concreta. De aquí que el pensamiento latinoamericano se distinga por una predominante posición crítica ante la condición subordinada del subcontinente y, en consecuencia, por una casi necesaria formulación de líneas de intervención para alcanzar un cambio posible (por ejemplo: Zea, 1976; Salazar, 2006; Beorlegui, 2010).

El hecho fundante de la conquista y la colonización por Europa dejó su marca de desigualdad en la estructura social, política y cultural de las repúblicas independientes que se irguieron en la zona desde comienzos del siglo XIX, luego complementada, a la vez que desplazada, por la sujeción a un nuevo poder externo: el de los Estados Unidos de Norteamérica, prolongación contemporánea de los viejos imperios.

Ya los ideólogos y protagonistas de las luchas anticoloniales, nativos sublevados primero (siglos XVI al XVIII) y criollos revolucionarios más tarde (siglo XIX), plantaron las bases de la busca de diferenciación identitaria, que representa el signo más persistente del subcontinente.

Hacia la segunda mitad del siglo XIX, la denominación "América Latina", que había emergido en el marco de la pugna entre Francia e Inglaterra por el control político del "Nuevo Mundo", comenzó a ser apropiada y resignificada por intelectuales de la región, aunque solo entre finales de los años 40 y principios de los 70 del siglo XX alcanzó un estatus de reconocimiento en los ámbitos académico y de las relaciones intergubernamentales. De esos años provienen el Centro de Estudios Superiores de Comunicación para 
América Latina (1959), la Asociación Latinoamericana de Investigadores de la Comunicación (1978) y la Federación Latinoamericana de Facultades de Comunicación Social (1981).

Latinoamérica se convirtió, entonces, en el nombre unificador de los pueblos situados al sur de la América anglosajona (Chaunu, 1976) y, en el plano ideológico, en la representación de su polo opuesto. Con la revolución cubana de 1959 emergió el antiimperialismo y poco más tarde la reflexión académica puso sobre la mesa la problemática de la dependencia, elementos ambos que, con matices, continúan vigentes como categorías e interrogantes para la discusión y la movilización social.

Las perspectivas de análisis de las ciencias sociales latinoamericanas (y dentro de ellas las de la comunicación, aunque no todas) asumen esa colocación antagónica como referencia, mas no en el sentido de que la espacialidad territorial sea determinante para la percepción y la interpretación, sino más bien en el de que la zona condensa una historia de violencia y explotación que hace posible otro horizonte de visibilidad y de esperanza. Los enfoques comunicacionales de la región operan también sobre esa base.

\section{Las matrices extra latinoamericanas}

Las principales teorías referidas a la comunicación están emparentadas con las teorías sociales generales clásicas (estructural-funcionalismo, crítica dialéctica, estructuralismo y sistemismo), elaboradas, como se sabe, en realidades distintas a la de América Latina.

Esas explicaciones sobre la naturaleza de la sociedad, su estructura y dinámica constituyen las matrices (teorías madre) de las que se derivan los modos tradicionales y predominantes de comprender la comunicación, que constituyen los abordajes. Otras fuentes también presentes, pero no preponderantes, son las teorías de la psicología social, la economía política, la cibernética, la lingüística y la semiología (Galindo, 2008).

Así, se puede evidenciar que en la especialidad se produjo una doble aplicación teórica: por un lado, el entendimiento del hecho comunicacional desde nociones ante todo de orden sociológico; por otro, la traslación de los conceptos euroestadounidenses a contextos geohistóricos diferentes de aquellos en que fueron originados.

Cada una de las teorías sociales generales mencionadas se organiza en torno a un principio de articulación conceptual y es un sistema de intelección de los fenómenos y procesos del mundo social, por lo que cada cual es capaz de ofrecer una determinada explicación o interpretación de los mismos. 
Cuando una de esas "matrices teóricas" es empleada para dar cuenta del campo comunicacional, en la codificación acáadoptada, se tiene un “abordaje teórico" (pragmático, crítico, sociotécnico o político-cultural) que, a su vez, puede desdoblarse en varios "enfoques teóricos", que serán teorizaciones de menor alcance referidas a subáreas del campo. Matriz, abordaje y enfoques están unidos por una línea de coherencia (una racionalidad) y cada uno de estos niveles de teoría implica un encuadramiento dado de la realidad observable (Torrico, 2010).

Se puede afirmar, entonces, que cada teoría supone un modo de mirar y comprender el objeto estudiado y, por tanto, conlleva una manera de dar razón de él y de hacer prescripciones al respecto: las matrices hablan de la totalidad social, los abordajes de la zona comunicacional y los enfoques de sectores o de fenómenos reconocibles dentro de esta zona.

Si bien todos estos parámetros formales descriptivos de la composición, alcances y fines de las teorías no representan mayor problema en su uso práctico, sí es necesario detenerse en las concepciones de realidad que esas teorías tienen como sustrato. Es ahí donde su correspondiente marca de nacimiento actúa como condicionante de la óptica que adoptará un determinado análisis.

\section{Tres corrientes teóricas principales}

En ese sentido, y en función de sus concepciones de fondo, en el espacio teórico de la comunicación es dable identificar tres grandes corrientes de pensamiento, esto es, tendencias en que convergen ideas y autores a partir de directrices generales o elementos particulares que se complementan y refuerzan entre sí, además de compartir una forma de leer la realidad social que les sirve de orientación. Esas corrientes son la pragmática, la crítica y la crítico-utópica.

La primera de ellas es la fundadora de los estudios comunicacionales. En lo epistemológico, su pragmatismo se expresa en que toma la utilidad y la eficacia como criterio de verdad. Es la corriente inaugurada por Harold Lasswell (1938) en los Estados Unidos a mediados de los años 20 del siglo pasado, centralmente preocupada por los efectos y la eficacia de la comunicación, y que, además, nutrió a la llamada mass communication research (consúltense los artículos de Lazarsfeld, Merton, Lasswell y Wright en De Moragas, 1982, pp. 171-223). Su interés radica en la reproducción del orden establecido.

La segunda, más bien de cuna europea y atribuible especialmente a los trabajos desarrollados por los miembros de la Escuela de Frankfurt, sobre 
todo en el decenio de 1940, pone en cuestión la irracionalidad del orden social existente y también la mercantilización de la cultura (la "industria cultural"), tanto como las consecuencias enajenadoras de la conciencia individual y colectiva que esta trae aparejadas. Plantea el conocimiento crítico de la sociedad y la necesidad de la emancipación, que supone la transformación social, pero no en la ruta del materialismo histórico (Bell et al., 1985, pp. 177-230; Marcuse, 1972).

Y la última, la crítico-utópica, es la surgida en América Latina al impulso de pensadores como Antonio Pasquali, Luis Ramiro Beltrán, Paulo Freire o Armand Mattelart a lo largo de las "décadas rebeldes": 1960 y 1970. Critica la concepción pragmática de la comunicación, denuncia las estructuras de propiedad oligárquicas de los sistemas de medios en la región, al igual que la reproducción teórico-metodológica acrítica, la dependencia en materia de contenidos y el uso de patrones de producción de mensajes. Propone democratizar los procesos comunicacionales y de la sociedad (Mattelart, 1970; Pasquali, 1977; Freire, 1981; Beltrán \& Fox, 1982; Atwood \& McAnany, 1986).

La primera corriente corresponde, con sus matices y variantes, a las matrices estructural-funcionalista, estructuralista y sistemista, en tanto que las otras dos guardan una relación no ortodoxa con la crítico-dialéctica. En cuanto a su relación con los abordajes, la primera halla sustento y expresión en el pragmático y el sociotécnico, la segunda en el crítico y la última en el político-cultural.

Cada uno de los abordajes, como ya fue dicho, se compone de varios enfoques (Torrico, 2010), que son las maneras en que la mirada analítica se concentra en el estudio del objeto comunicacional (el proceso) o algunos de sus elementos desde una posición teórico-metodológica guiada por el respectivo abordaje y, en última instancia, por la concepción matricial que le da sentido.

Si bien es el interior de las corrientes pragmática y crítica donde se generaron los principales enfoques teóricos, que ya pueden ser considerados tradicionales, la corriente crítico-utópica hizo otras aportaciones, que son las que se presentan a continuación.

\section{Los enfoques latinoamericanos}

El análisis efectuado de las conceptualizaciones de comunicación propuestas explícitamente por pensadores de Argentina, Bolivia, Brasil, Colombia, Chile, México, Paraguay, Perú, Uruguay y Venezuela durante las décadas de 1960 a 2000 (Torrico, 2016a) permitió reconocer la utilización de 19 enfoques teóricos en los estudios latinoamericanos de la especialidad. 
Nueve de esos enfoques pertenecen a la tradición euroestadounidense, a saber: las estructuras significantes, la ideología dominante, la generación de efectos, la transmisión eficiente y eficaz, las estructuras de los mensajes, la construcción de hegemonía, la acción comunicativa, el consumo cultural y las mediaciones. ${ }^{3}$ En todos estos casos se trata de aplicaciones de esas formas comprensivas extrarregionales hechas por un grupo de autores en América Latina.

Pero otro conjunto de comunicólogos de la zona produjo una decena de enfoques originales, cuyas denominaciones han sido asignadas tomando como base sus conceptos o propósitos centrales.

A continuación se ofrece un desglose de esas contribuciones teóricas latinoamericanas junto a la mención de sus autores de referencia, la noción de comunicación a la que remiten y sus principios generales o reglas de pensamiento:

Comunicación
número 41
Julio-diciembre
2019

3 Los antecedentes de estos dos últimos enfoques, que a veces aparecen como latinoamericanos por los trabajos de Néstor García Canclini y Jesús MartínBarbero, están en la obra de Pierre Bourdieu (1988 y 2010) y Manuel Martín Serrano (1977), respectivamente.

\section{Tabla. Enfoques comunicacionales latinoamericanos}

\begin{tabular}{|c|c|c|c|}
\hline Denominación & Autor(es) & Noción de comunicación & Principio general \\
\hline Con-saber & $\begin{array}{l}\text { Antonio Pasquali } \\
\text { (Venezuela) }\end{array}$ & $\begin{array}{l}\text { La comunicación es una relación } \\
\text { esencial de la convivencia y la } \\
\text { socialidad caracterizada por la } \\
\text { reciprocidad y la bivalencia entre } \\
\text { transmisor y receptor. }\end{array}$ & $\begin{array}{l}\text { Las relaciones paritarias y bivalentes entre transmisor } \\
\text { y receptor hacen posible tanto la construcción como el } \\
\text { intercambio de un con-saber; esto es, de un saber-con-el- } \\
\text { otro. Estas relaciones son privativas de los seres racionales } \\
\text { aptos para el comportamiento comunicacional y social en } \\
\text { los niveles sensorial e intelectual. }\end{array}$ \\
\hline Dialogicidad & $\begin{array}{l}\text { Paulo Freire } \\
\text { (Brasil) }\end{array}$ & $\begin{array}{l}\text { La comunicación es un diálogo } \\
\text { entre interlocutores mediado por } \\
\text { un código común, y hace posible el } \\
\text { mundo social y el conocimiento. }\end{array}$ & $\begin{array}{l}\text { La vida humana solo tiene sentido en la comunicación. } \\
\text { Se tiene que superar la “cultura del silencio", la de los } \\
\text { "comunicados", con la problematización crítica y dialógica } \\
\text { que restablezca la comunicación. El diálogo, el aprendizaje } \\
\text { en comunidad, es parte de la exigencia radical de } \\
\text { transformar objetivamente la situación social de opresión. }\end{array}$ \\
\hline Simbolización & $\begin{array}{l}\text { Luiz Beltrão } \\
\text { (Brasil), Luiz } \\
\text { Martino (Brasil) }\end{array}$ & $\begin{array}{l}\text { La comunicación es el intercambio } \\
\text { simbólico, base de las relaciones } \\
\text { humanas, orientado al diálogo y a } \\
\text { la acción conjunta. }\end{array}$ & $\begin{array}{l}\text { El ser humano, con su capacidad de producir sentidos, ha } \\
\text { desarrollado un universo simbólico que constituye la trama } \\
\text { de las relaciones sociales y media, cada vez más, su relación } \\
\text { con la realidad física. La posibilidad de generar, compartir e } \\
\text { interpretar representaciones abstractas (símbolos), así como } \\
\text { de emplear el lenguaje proposicional, es exclusivamente hu- } \\
\text { mana. }\end{array}$ \\
\hline $\begin{array}{l}\text { Comunicación } \\
\text { horizontal }\end{array}$ & $\begin{array}{l}\text { Luis Ramiro } \\
\text { Beltrán (Bolivia), } \\
\text { Frank Gerace } \\
\text { (Estados Unidos } \\
\text { de Norteamérica) }\end{array}$ & $\begin{array}{l}\text { La comunicación es el proceso de } \\
\text { interacción social democrática en } \\
\text { un marco de derechos, libertades y } \\
\text { participación. }\end{array}$ & $\begin{array}{l}\text { Los seres humanos son comunicadores que tienen el dere- } \\
\text { cho natural de emitir y recibir mensajes en un proceso de } \\
\text { interacción simbólica equilibrada, con múltiples finalidades } \\
\text { y en condiciones de acceso libre e igualitario, diálogo y par- } \\
\text { ticipación. }\end{array}$ \\
\hline $\begin{array}{l}\text { Comunicación } \\
\text { participativa }\end{array}$ & $\begin{array}{l}\text { Fernando Reyes } \\
\text { Matta (Chile), } \\
\text { Mario Kaplún } \\
\text { (Uruguay) }\end{array}$ & $\begin{array}{l}\text { La comunicación es un proceso } \\
\text { dinámico que requiere del acceso y } \\
\text { la participación. }\end{array}$ & $\begin{array}{l}\text { La participación va más allá de la recepción crítica y de } \\
\text { la democratización de las comunicaciones. Implica la } \\
\text { intervención efectiva de los grupos marginalizados en la } \\
\text { producción y orientación de los mensajes, y debe expresar } \\
\text { su compromiso activo en la vida pública. }\end{array}$ \\
\hline
\end{tabular}




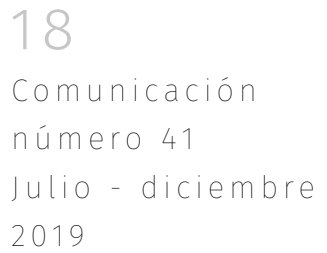

\begin{tabular}{|c|c|c|c|}
\hline Denominación & Autor(es) & Noción de comunicación & Principio general \\
\hline $\begin{array}{l}\text { Comunicación } \\
\text { alternativa y } \\
\text { popular }\end{array}$ & $\begin{array}{l}\text { Diego Portales } \\
\text { (Chile), } \\
\text { Daniel Prieto } \\
\text { (Argentina), } \\
\text { Armand Mattelart } \\
\text { (Bélgica) }\end{array}$ & $\begin{array}{l}\text { La comunicación alternativa } \\
\text { contrarresta a la transnacional } \\
\text { con amplia participación social, } \\
\text { flujos democráticos de mensajes y } \\
\text { orientación al cambio social. }\end{array}$ & $\begin{array}{l}\text { Los sectores marginales y populares de las sociedades } \\
\text { dependientes deben desarrollar una comunicación } \\
\text { contestataria inserta en estrategias de cambio social y } \\
\text { opuesta a las prácticas de los medios comerciales y de las } \\
\text { estructuras transnacionales. }\end{array}$ \\
\hline $\begin{array}{l}\text { Comunicación } \\
\text { cohesionadora }\end{array}$ & $\begin{array}{l}\text { Francisco Gil } \\
\text { (Colombia), } \\
\text { Amaro La Rosa } \\
\text { (Perú), Francisco } \\
\text { Rüdiger (Brasil) }\end{array}$ & $\begin{array}{l}\text { La comunicación es el intercambio } \\
\text { de ideas e informaciones que } \\
\text { cohesiona la sociedad y produce la } \\
\text { cultura. }\end{array}$ & $\begin{array}{l}\text { La comunicación es el proceso primario de intercambio de } \\
\text { mensajes entre seres humanos que posibilita la unidad y la } \\
\text { estabilidad del todo social. }\end{array}$ \\
\hline $\begin{array}{l}\text { Comunicación } \\
\text { fundante }\end{array}$ & $\begin{array}{l}\text { Juan Díaz } \\
\text { Bordenave } \\
\text { (Paraguay), } \\
\text { Héctor Schmucler } \\
\text { (Argentina), } \\
\text { Severo Iglesias } \\
\text { (México), Felipe } \\
\text { López (México), } \\
\text { Rosa María Alfaro } \\
\text { (Perú), Daniel } \\
\text { Hernández } \\
\text { (Venezuela) }\end{array}$ & $\begin{array}{l}\text { La comunicación es un proceso de } \\
\text { interacción mediante signos que } \\
\text { constituye al hombre social. }\end{array}$ & $\begin{array}{l}\text { La comunicación es uno de los principios de la hominización } \\
\text { y de la existencia social. Sin el lenguaje abstracto y } \\
\text { proposicional, los seres humanos no serían lo que son; sin } \\
\text { la relación básica que ella supone entre dos o más seres } \\
\text { humanos no existiría la sociedad. }\end{array}$ \\
\hline $\begin{array}{l}\text { Derecho a la } \\
\text { comunicación }\end{array}$ & $\begin{array}{l}\text { José Marques de } \\
\text { Melo (Brasil), Luis } \\
\text { Ramiro Beltrán } \\
\text { (Bolivia) }\end{array}$ & $\begin{array}{l}\text { La comunicación es un proceso de } \\
\text { diálogo y acción común que, en } \\
\text { tanto patrimonio colectivo, es un } \\
\text { derecho social. }\end{array}$ & $\begin{array}{l}\text { La profundización de la democracia conlleva la ampliación } \\
\text { de la participación ciudadana en la dinámica de toma } \\
\text { de decisiones en la vida pública y en los procesos } \\
\text { comunicacionales correspondientes. La facultad de } \\
\text { comunicar y estar comunicados debe ser legalmente } \\
\text { garantizada para todas las personas. }\end{array}$ \\
\hline $\begin{array}{l}\text { Producción de } \\
\text { sentido }\end{array}$ & $\begin{array}{l}\text { Raúl Fuentes } \\
\text { Navarro (México), } \\
\text { Rossana Reguillo } \\
\text { (México), } \\
\text { Eduardo Vizer } \\
\text { (Argentina), Vera } \\
\text { Veiga (Brasil), } \\
\text { Enrique Sánchez } \\
\text { (México), Marta } \\
\text { Rizo (México) }\end{array}$ & $\begin{array}{l}\text { La comunicación es la interacción } \\
\text { discursiva entre sujetos } \\
\text { históricamente situados que } \\
\text { produce sentidos sobre el entorno. }\end{array}$ & $\begin{array}{l}\text { El sentido de la comunicación se produce como resultado de } \\
\text { la sinergia entre enunciador, medio, discurso, destinatario } \\
\text { y contextos de enunciación y recepción. El sentido no } \\
\text { preexiste, a priori, en el contenido, sino que se genera en el } \\
\text { acontecer de la relación de comunicación. }\end{array}$ \\
\hline
\end{tabular}

Fuente: Elaboración propia.

Estos 10 enfoques sintetizan el espíritu del pensamiento latinoamericano referido a la comunicación, el mismo que, a lo largo de las últimas cinco décadas, ha confirmado su talante crítico, al tiempo que ha persistido en el diseño de un futuro con justicia y libertad.

Al margen de que cada enfoque priorice un determinado aspecto, atributo o finalidad del proceso comunicacional, es factible señalar estos rasgos que más bien aparecen recurrentemente en las miradas teóricas regionales: 
- El cuestionamiento y la oposición a la unidireccionalidad del proceso de transmisión y a la búsqueda de efectos, ambas propias de la concepción pragmática.

- La primacía otorgada al intercambio y la interrelación, al diálogo posible.

- La reivindicación de la humanidad de los sujetos involucrados en toda relación de comunicación.

- La defensa del derecho social a la comunicación y de las condiciones para que tenga realidad.

- La postulación y promoción de la democratización comunicacional y de la sociedad.

- La búsqueda del restablecimiento del significado y el propósito comunitario de la comunicación.

Todo esto indica que América Latina posee una concepción propia de la comunicación como proceso social de (inter)relación significante, que, a su vez, es el basamento sobre el que se constituye el campo de conocimiento especializado, la comunicación o comunicología.

\section{Una episteme propia}

Los enfoques teóricos de América Latina (no los meramente reproductivos de las corrientes de cuño euroestadounidense, sino los que ponen en cuestión la estructura asimétrica e instrumentalizadora de la comunicación que prevalece en aquellas) comparten un código crítico que ordena las percepciones e interpretaciones sobre el hecho comunicacional desde la condición de subalternidad (otredad subordinada) en que se encuentra la región (Torrico, 2016b).

Tal es el fundamento de la "episteme" propia que concibe a la comunicación como un proceso humano-social constitutivo e imbrica su conocimiento y práctica con el interés público y la lucha por la democratización.

De aquí que la perspectiva comunicacional latinoamericana conjugue el camino utópico de una sociedad con derechos y la potencia intelectual subversiva que puede desmontar los andamiajes de la desigualdad y la exclusión.

\section{Referencias}

Atwood, R. \& McAnany, E. (1986). Communication e Latin American society. Trends in critical research, 1960-1985. The University of Wisconsin Press.

Bell, D. et al. (1985). Industria cultural y sociedad de masas. Monte Ávila. 
Beltrán, L. ([1979] 2007). Adiós a Aristóteles: la comunicación “horizontal”. Revista Latinoamericana de Ciencias de la Comunicación, (7), 12-36.

Beltrán, L. \& Fox, E. (1982). Comunicação dominada. Os Estados Unidos e os meios de comunicação da América Latina. Paz e Terra.

Beltrán, L. (2000). Investigación sobre comunicación en Latinoamérica. Inicio, trascendencia y proyección. La Paz.

Beltrão, L. (1980). Teoria geral da comunicação. Thesaurus.

Beorlegui, C. (2010). Historia del pensamiento filosófico latinoamericano. Una búsqueda incesante de la identidad (3. ${ }^{a}$ ed.). Universidad de Deusto.

Bourdieu, P. (1988). La distinción. Criterios y bases sociales del gusto. Santillana.

Bourdieu, P. (2010). El sentido social del gusto. Elementos para una sociología de la cultura. Siglo XXI.

Chaunu, P. (1976). Historia de América Latina. Eudeba.

De Moragas, M. (Edit.) (1982). Sociología de la comunicación de masas (7. ed.ed.). G. Gili.

Díaz Bordenave, J. (1984). Além dos meios e mensagens. Introdução à comunicação como processo, tecnologia, sistema e ciência. Vozes.

Escobar, A. (2018). Otro posible es posible: caminando hacia las transiciones desde Abya Yala/Afro/Latino-América. Desde Abajo.

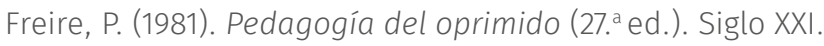

Fuentes, R. (1991). Un campo cargado de futuro. El estudio de la comunicación en América Latina. Iteso.

Galindo, J. (Coord.) (2008). Comunicación, ciencia e historia. Fuentes científicas históricas hacia una comunicología posible. McGraw Hill.

Gil, F. (1978). Iniciación a la comunicación social (2. ${ }^{a}$ ed.). Paulinas.

Gobbi, M. (2008). A batalha pela hegemonia comunicacional na América Latina. 30 anos da ALAIC. Universidade Metodista de São Paulo.

Lasswell, H. ([1927] 1938). Propaganda technique in the World War. Peter Smith.

Maldonado, E. (2015). Epistemología de la comunicación. Análisis de la vertiente Mattelart en América Latina. Ciespal.

Marcuse, H. (1972). Razón y revolución (2. ${ }^{a}$ ed.). Alianza.

Marques de Melo, J. (2007). Entre el saber y el poder. Pensamiento comunicacional latinoamericano. Unesco.

Martín-Barbero, J. (1998). De los medios a las mediaciones. Convenio Andrés Bello.

Martín Serrano, M. (1977). La mediación social. Akal.

Mattelart, A. (1970). Críticas a la communication research. Cuadernos de la Realidad Nacional, (3), 11-22.

Mattelart, A. \& Mattelart, M. (1989). Pensar sobre los medios. Comunicación y crítica social. UAMX.

Pasquali, A. (1977). Comunicación y cultura de masas (4. ${ }^{a}$ ed.). Monte Ávila.

Pasquali, A. (1985). Comprender la comunicación. Monte Ávila.

Prieto, D. (1991). Discurso autoritario y comunicación alternativa (5. ed.). Premiá.

Reguillo, R. (1995). En la calle otra vez. Las Bandas: identidad urbana y usos de las comunicaciones. Iteso.

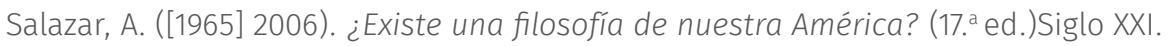


Schmucler, H. (1997). Memoria de la comunicación. Biblos.

Torrico, E. (2010). Comunicación. De las matrices a los enfoques. Ciespal.

Torrico, E. (2016a). La comunicación pensada desde América Latina (1960-2009). Comunicación Social.

Torrico, E. (2016b). La comunicación en clave latinoamericana. Chasqui. Revista Latinoamericana de Comunicación, (132), 23-36.

Zavaleta, R. (1988). Clases sociales y conocimiento. Los Amigos del Libro.

Zea, L. ([1965] 1976). El pensamiento latinoamericano (3. ${ }^{\text {a ed. }}$.). Ariel.

Zea, L. (Coord.) ([1986] 2006). América Latina en sus ideas (4. a ed.). Siglo XXI. 